\title{
Improving Dimensional Stability of Visible Light-cured Trial Denture Base using Different Colored Casts
}

\section{Sahar Elkholy}

\section{ABSTRACT}

Purpose: This study aimed to evaluate the effects of the color of the cast on dimensional stability of visible light-cured (VLC) trial denture bases.

Materials and methods: A total of 60 VLC acrylic resin trial denture bases were fabricated on different colored casts ( 20 white, 20 dark blue, and 20 dark brown casts) and were divided into two groups; each group consisted of 30 casts (10 white, 10 dark blue, and 10 dark brown). The gap between the base and the cast after 24 hours was measured at different points (left crest of the ridge, midpalatal area, and right crest of the ridge) at the posterior and premolar areas for group I and after 48 hours for group II by using a stereomicroscope.

Results: With brown cast, the trial denture base showed significant decrease in dimensional change in comparison with white and blue casts after 24 and 48 hours.

Conclusion: The dimensional accuracy of the VLC trial denture base could be improved by using dark-colored cast during construction, to ensure accurate maxillomandibular relationship and accurate evaluation of phonetics and esthetic of wax trial dentures.

Keywords: Denture, Dimensional stability, Record base, Trial denture base, Visible light-cured resin.

How to cite this article: Elkholy S. Improving Dimensional Stability of Visible Light-cured Trial Denture Base using Different Colored Casts. J Contemp Dent 2016;6(3):171-176.

Source of support: Nil

Conflict of interest: None

\section{INTRODUCTION}

An accurate and dimensionally stable trial denture base is mandatory for the construction of dentures. Trial denture bases are used for recording jaw relation, setting of artificial teeth, and for giving the full future idea about final denture. ${ }^{1}$

It is said that the accuracy of jaw relation record is affected by the accuracy, stiffness, and stability of the record base. Stable record base is critical for evaluation of the esthetics and phonetics of the wax trial prosthesis. ${ }^{2}$

\footnotetext{
Associate Professor

Department of Implant and Removable Prosthodontics, Pharos University in Alexandria, Alexandria, Egypt

Corresponding Author: Sahar Elkholy, Associate Professor Department of Implant and Removable Prosthodontics, Pharos University in Alexandria, Alexandria, Egypt, e-mail: sahar. elkholy@pua.edu.eg
}

To ensure intraoral stability and retention of the record base, the base should maintain close adaptation to the cast and be dimensionally stable.

Among the various methods and materials for fabricating record base, there are two types that are commonly used. One is the temporary record base made of autopolymerizing resin or light-curing resin and the other is the permanent record base made of heat-curing resin, or noble metal or base metal. ${ }^{3,4}$

When choosing record base material, the price, strength, stability, easy of fabrication method, and colors should be considered. ${ }^{2}$

Since the 1990s, visible light-cured (VLC) acrylic resin material has been used in the curriculum of dental schools worldwide as an alternative to the chemical acrylic resin material.

The light-curing resin is composed of urethane dimethacrylate matrix and a small amount of silica, which adjusts flow. ${ }^{5,6}$

There is no need to mix powder and liquid; therefore, it does not harm human bodies due to inhaling of the poisonous smell and powder. Also, it can be dealt with hands harmlessly because it needs no liquid. It is easy to make and is economical due to less waste of material. ${ }^{7}$

Visible light-cured acrylic resin has many advantages, such as short preparation time, ease of use, strength and rigidity, and uniform thickness.

However, there are some disadvantages, such as the additional expense of a special light polymerizing unit, stickiness on the surface once cured, poor finish, and the hardness of the material making it more difficult to trim. ${ }^{8,9}$

However, the main disadvantage was dimensional instability. Many researchers reported that it must be used immediately after polymerization, which is inconvenient to the majority of clinicians. ${ }^{10,11}$

The purpose of this study was to evaluate the dimensional stability of VLC trial denture bases fabricated on different colored casts (whit, blue, and brown casts).

\section{MATERIALS AND METHODS}

\section{Sample Preparation}

Upper edentulous silicon mold was made. A total of 60 maxillary edentulous casts were poured with dental stone divided into two main groups (A and B); each group consisted of 30 casts. 
Groups I and II were divided into three subgroups; each subgroup consisted of 10 casts.

1. The first subgroup casts were poured with white stone.

2. The second subgroup casts were poured with dark blue stone (stone mixed with dark blue stain).

3. The third subgroup casts were poured with dark brown stone (stone mixed with dark brown stain).

A total of 60 trial denture bases were fabricated using VLC acrylic resin by close adaptation of the VLC sheet to the cast, starting from the center toward the periphery, and the excess material was cut by scalpel. The trial denture bases were put on a curing unit for 5 minutes; after that the bases were removed from the cast and were inverted to expose the underside to the light and cured for more than 5 minutes.

The gap between the base and the cast of group I was measured after 24 hours by using a stereomicroscope at three points - left crest of the ridge, midpalatal area, and right crest of the ridge as measuring points $\mathrm{A}, \mathrm{B}$, and $\mathrm{C}$ (Fig. 1). The cast and trial denture bases were cut using diamond saw at premolar molar region, which was about $25 \mathrm{~mm}$ from the posterior border. The gap between the trial denture base and the cast was measured at the left crest of the ridge, midpalatal area, and right crest of the ridge as measuring points $\mathrm{A}^{-}, \mathrm{B}^{-}$, and $\mathrm{C}^{-}$.

After 48 hours, the same procedure was done with group $B$, and the gap between the base and the cast was measured at six points $\mathrm{A}, \mathrm{B}, \mathrm{C}$ and $\mathrm{A}^{-}, \mathrm{B}^{-}, \mathrm{C}^{-}$.

\section{Measuring the Accuracy}

The gap between the master cast and the trial denture base was measured at each measuring point with the rate of 50 times using stereomicroscope SZ-ST (Olympus, Japan) (Fig. 2).

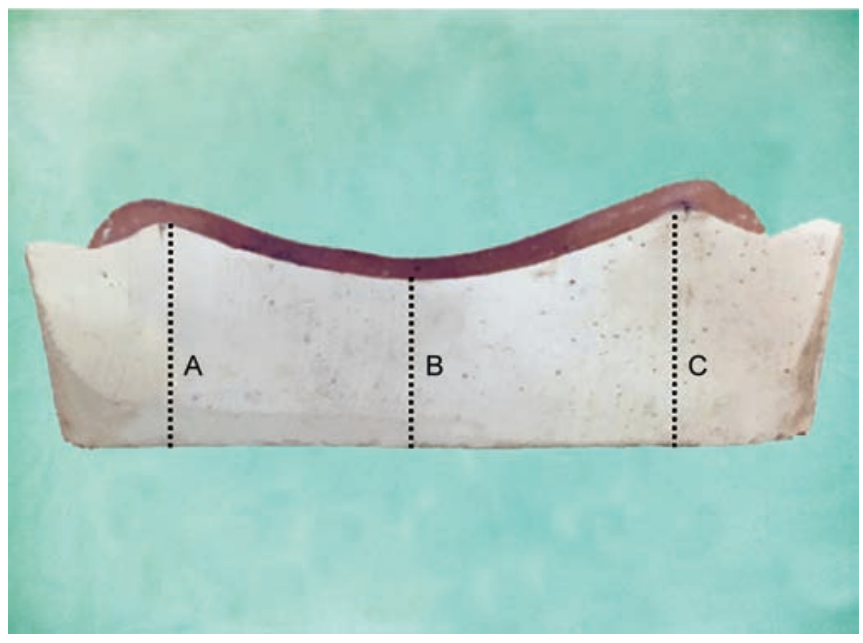

Figs 1A to C: Three measuring points at posterior palatal area. (A) Left crest of the ridge; (B) midpalatal area; and (C) right crest of the ridge

\section{Statistical Analysis}

Data were analyzed using Statistical Package for the Social Sciences (SPSS) software package version 18.0 (SPSS, Chicago, IL, USA). Quantitative data were expressed using range, mean, standard deviation, and median. Non-normally distributed quantitative data were analyzed using Mann-Whitney U test for comparing two groups, while for more than two groups, the Kruskal-Wallis test was applied. The $p$-value was assumed to be significant at $\leq 0.05$.

\section{RESULTS}

\section{Accuracy according to the Points and Color of the Cast}

From the results of the present study in Table 1, it was found that point $B$ (midposterior palatal area) represents the most dimensionally unstable point, followed by point $A$ (left crest), and point C (right crest) was the least dimensionally unstable point after 24 hours with white and blue casts. Trial denture base that was constructed on brown cast showed that the least dimensional change was at point $C$ (right crest) followed by point $B$ (midposterior palatal area), and point $\mathrm{A}$ (left crest) showed the most dimensionally unstable point. There was significant increase in accuracy at point $B$ in comparison with white and blue casts (Figs 3 to 5).

After 48 hours, it was found that point B (midposterior palatal area) represented the most dimensionally unstable point followed by point $\mathrm{A}$ (left crest), and point $\mathrm{C}$ (right crest) was the least dimensionally unstable point with white, blue, and brown casts.

At premolar-molar region in Table 2, it was found that point $\mathrm{B}^{-}$(mid palatal area) represented the most dimensionally unstable area, followed by point $\mathrm{A}^{-}$(left crest), and point $\mathrm{C}^{-}$(right crest) was the least dimensionally

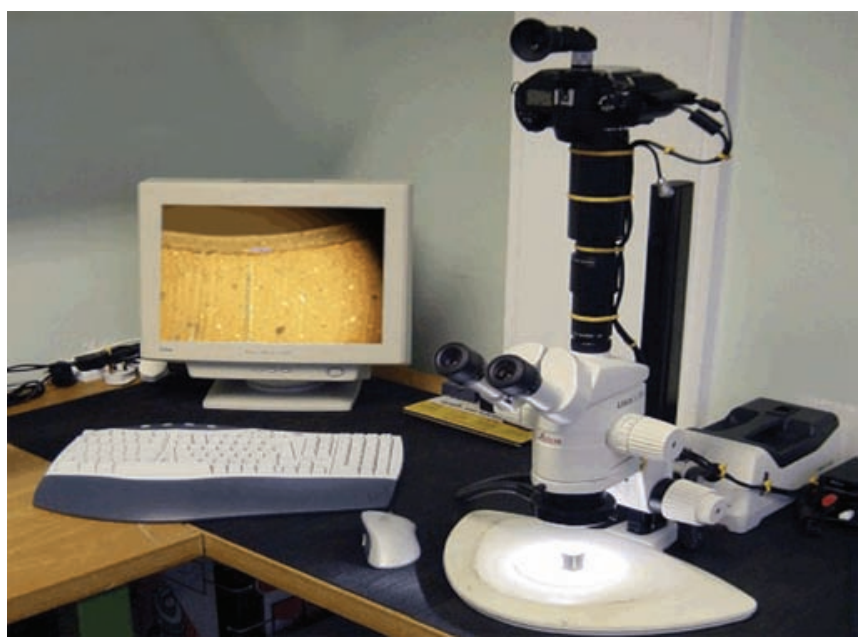

Fig. 2: Stereomicroscope 
Improving Dimensional Stability of Visible Light-cured Trial Denture Base using Different Colored Casts

Table 1: Comparison between the studied groups according to point in color at posterior palatal area

\begin{tabular}{|c|c|c|c|c|c|c|}
\hline & & White & Blue & Brown & $K W \chi^{2}$ & $p$-value \\
\hline \multirow[t]{9}{*}{ Point $\mathrm{A}$} & 24 hours & & & & & \\
\hline & Min. - Max. & $68.88-266.99$ & $92.61-179.69$ & $89.84-134.76$ & $6.745^{\star}$ & $0.034^{*}$ \\
\hline & Mean \pm SD & $195.45 \pm 62.33$ & $123.99^{a} \pm 30.37$ & $107.81^{\mathrm{a}} \pm 18.79$ & & \\
\hline & Median & 212.99 & 112.30 & 112.30 & & \\
\hline & 48 hours & & & & & \\
\hline & Min. - Max. & $67.38-449.29$ & $157.22-606.44$ & $134.76-269.53$ & 0.725 & 0.696 \\
\hline & Mean \pm SD & $224.64 \pm 115.03$ & $283.57 \pm 141.51$ & $218.99 \pm 49.14$ & & \\
\hline & Median & 213.48 & 247.07 & 213.38 & & \\
\hline & $\mathrm{p}_{1}$ & 0.866 & $0.027^{\star}$ & $0.043^{*}$ & & \\
\hline \multirow[t]{9}{*}{ Point B } & 24 hours & & & & & \\
\hline & Min. - Max. & $271.58-728.0$ & $134.76-269.53$ & $89.84-112.30$ & $15.241^{*}$ & $<0.001^{*}$ \\
\hline & Mean \pm SD & $451.47 \pm 190.59$ & $188.22^{\mathrm{a}} \pm 64.05$ & $94.33^{\mathrm{ab}} \pm 10.04$ & & \\
\hline & Median & 345.33 & 160.37 & 89.84 & & \\
\hline & 48 hours & & & & & \\
\hline & Min. - Max. & $67.38-449.21$ & $314.45-808.58$ & $157.22-404.29$ & $10.838^{*}$ & $0.004^{*}$ \\
\hline & Mean \pm SD & $280.82 \pm 122.30$ & $522.21^{a} \pm 165.81$ & $272.34^{b} \pm 73.46$ & & \\
\hline & Median & 258.30 & 516.60 & 269.53 & & \\
\hline & $\mathrm{p}_{1}$ & $0.028^{*}$ & $0.028^{*}$ & $0.042^{*}$ & & \\
\hline \multirow[t]{9}{*}{ Point C } & 24 hours & & & & & \\
\hline & Min. - Max. & $88.44-282.05$ & $89.84-247.07$ & $67.38-112.30$ & $7.643^{*}$ & $0.022^{*}$ \\
\hline & Mean \pm SD & $215.91 \pm 67.34$ & $160.97 \pm 53.94$ & $89.84^{a} \pm 15.88$ & & \\
\hline & Median & 243.99 & 157.23 & 89.84 & & \\
\hline & 48 hours & & & & & \\
\hline & Min. - Max. & $67.38-404.29$ & $269.53-696.28$ & $112.30-336.91$ & $9.556^{*}$ & $0.008^{*}$ \\
\hline & Mean \pm SD & $253.81 \pm 99.35$ & $407.10^{a} \pm 142.27$ & $224.61^{b} \pm 67.92$ & & \\
\hline & Median & 269.53 & 404.29 & 202.15 & & \\
\hline & $\mathrm{p}_{1}$ & 0.499 & $0.027^{*}$ & 0.059 & & \\
\hline
\end{tabular}

$\mathrm{KW}^{2}$ : Chi-square test for Kruskal-Wallis test; Sig. bet. grps was done using Mann-Whitney test; $\mathrm{p}_{1}$ : $\mathrm{p}$-value for Wilcoxon signed ranks

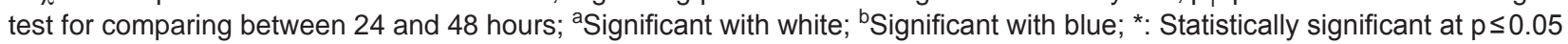

Table 2: Comparison between the studied groups according to point in color at premolar-molar area

\begin{tabular}{|c|c|c|c|c|c|c|}
\hline & & White & Blue & Brown & $K W \chi^{2}$ & $p$-value \\
\hline \multirow[t]{9}{*}{ Point $\mathrm{A}^{-}$} & After 24 hours & & & & & \\
\hline & Min. - Max. & $66.10-264.99$ & $134.76-247.07$ & $67.38-179.69$ & 3.837 & 0.147 \\
\hline & Mean \pm SD & $187.40 \pm 73.35$ & $164.71 \pm 41.82$ & $112.30 \pm 42.02$ & & \\
\hline & Median & 196.03 & 157.22 & 112.30 & & \\
\hline & After 48 hours & & & & & \\
\hline & Min. - Max. & $112.30-471.67$ & $291.99-516.59$ & $67.38-269.53$ & $11.000 *$ & $0.004^{*}$ \\
\hline & Mean \pm SD & $260.54 \pm 110.64$ & $362.18^{\mathrm{a}} \pm 83.55$ & $193.73^{b} \pm 64.59$ & & \\
\hline & Median & 235.84 & 336.91 & 202.15 & & \\
\hline & $\mathrm{p}_{1}$ & $0.046^{*}$ & $0.028^{*}$ & $0.043^{*}$ & & \\
\hline \multirow[t]{9}{*}{ Point $\mathrm{B}^{-}$} & After 24 hours & & & & & \\
\hline & Min. - Max. & $201.88-561.88$ & $157.22-656.28$ & $67.38-269.53$ & 5.435 & 0.066 \\
\hline & Mean \pm SD & $368.44 \pm 149.44$ & $345.22 \pm 211.50$ & $157.22^{\mathrm{a}} \pm 85.53$ & & \\
\hline & Median & 344.80 & 258.30 & 112.30 & & \\
\hline & After 48 hours & & & & & \\
\hline & Min. - Max. & $224.61-741.20$ & $471.67-920.89$ & $134.76-381.83$ & $16.255^{*}$ & $<0.001^{*}$ \\
\hline & Mean \pm SD & $523.38 \pm 182.19$ & $744.01^{a} \pm 156.74$ & $249.88^{a b} \pm 81.81$ & & \\
\hline & Median & 550.29 & 752.43 & 235.84 & & \\
\hline & $\mathrm{p}_{1}$ & $0.028^{*}$ & $0.028^{*}$ & 0.080 & & \\
\hline \multirow[t]{9}{*}{ Point $\mathrm{C}^{-}$} & After 24 hours & & & & & \\
\hline & Min. - Max. & $66.66-303.88$ & $157.22-247.07$ & $67.38-179.69$ & $6.395^{\star}$ & $0.041^{*}$ \\
\hline & Mean \pm SD & $215.79 \pm 76.77$ & $198.40 \pm 41.21$ & $103.32^{\mathrm{ab}} \pm 43.79$ & & \\
\hline & Median & 223.87 & 190.92 & 89.84 & & \\
\hline & After 48 hours & & & & & \\
\hline & Min. - Max. & $179.69-471.67$ & $247.07-741.20$ & $134.76-269.53$ & $13.181^{*}$ & $0.001^{*}$ \\
\hline & Mean \pm SD & $285.25 \pm 98.78$ & $471.72^{\mathrm{a}} \pm 182.12$ & $190.92^{\mathrm{ab}} \pm 50.94$ & & \\
\hline & Median & 247.07 & 415.52 & 179.69 & & \\
\hline & $\mathrm{p}_{1}$ & 0.063 & $0.028^{*}$ & $0.043^{*}$ & & \\
\hline
\end{tabular}

$\mathrm{KW}^{2}$ : Chi-square test for Kruskal-Wallis test; Sig. bet. grps was done using Mann-Whitney test; $\mathrm{p}_{1}$ : $\mathrm{p}$ value for Wilcoxon signed ranks test for comparing between 24 and 48 hours; ${ }^{a}$ Significant with white; ${ }^{b}$ Significant with blue; *Statistically significant at $p \leq 0.05$ 
Table 3: Comparison between the studied groups according to total points

\begin{tabular}{|c|c|c|c|c|c|}
\hline Mean points & White & Blue & Brown & $K W \chi^{2}$ & $p$-value \\
\hline \multicolumn{6}{|l|}{ After 24 hours } \\
\hline Min. - Max. & $129.58-364.23$ & $113.30-323.57$ & $82.35-449.97$ & $13.963^{*}$ & $0.001^{*}$ \\
\hline Mean \pm SD & $273.26 \pm 77.02$ & $196.92^{\mathrm{a}} \pm 61.60$ & $144.57^{\mathrm{ab}} \pm 112.89$ & & \\
\hline Median & 267.69 & 179.68 & 97.33 & & \\
\hline \multicolumn{6}{|l|}{ After 48 hours } \\
\hline Min. - Max. & $67.38-546.54$ & $269.53-666.33$ & $142.25-291.99$ & $28.613^{*}$ & $<0.001^{*}$ \\
\hline Mean \pm SD & $304.4 \pm 108.38$ & $465.13^{a} \pm 116.19$ & $225.08^{\mathrm{ab}} \pm 38.22$ & & \\
\hline Median & 306.96 & 456.70 & 228.35 & & \\
\hline $\mathrm{p}_{1}$ & 0.124 & $0.002^{*}$ & 0.074 & & \\
\hline
\end{tabular}

${ }^{\mathrm{kW}} \chi^{2}$ : Chi-square test for Kruskal-Wallis test; Sig. bet. grps was done using Mann-Whitney test; $p_{1}: p$ value for Wilcoxon signed ranks test for comparing between 24 and 48 hours; ${ }^{a}$ Significant with white; bSignificant with blue; * Statistically significant at $p \leq 0.05$

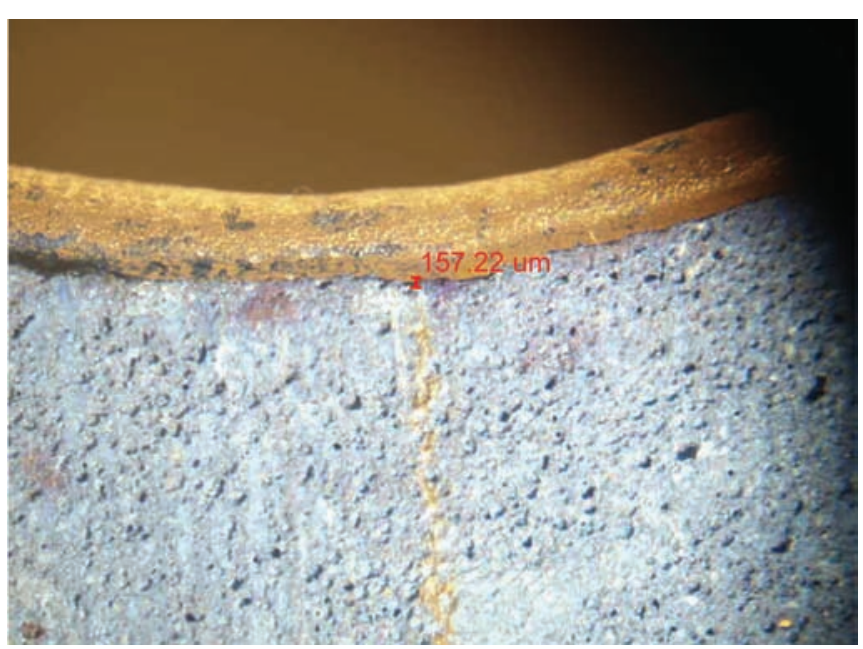

Fig. 3: Midposterior palatal area on blue cast

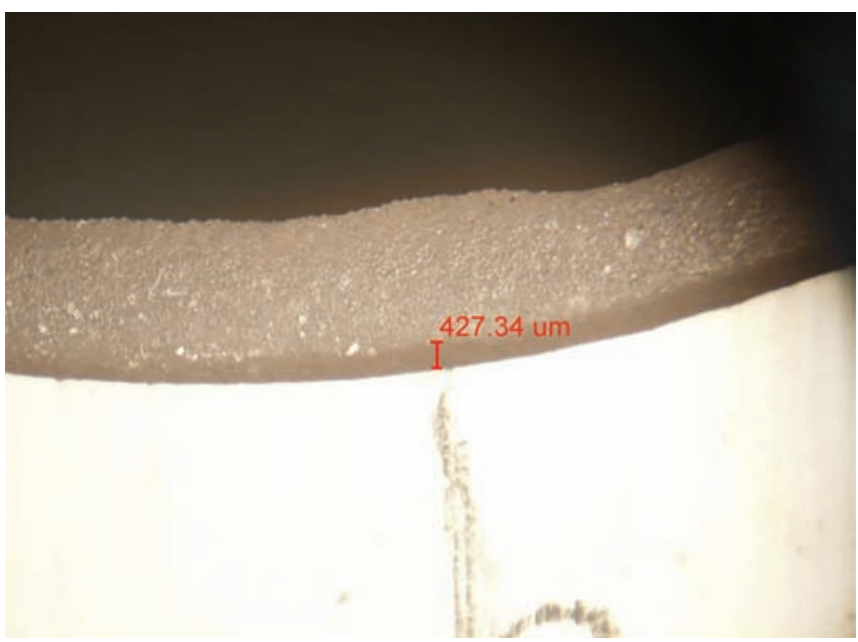

Fig. 5: Midposterior palatal area on white cast

unstable point after 24 and 48 hours with white, blue, and brown casts.

\section{Accuracy according to the Time and Color of the Cast to Total Points}

From the results in Table 3, there was a significant increase in accuracy with brown cast in comparison with blue and white casts after 24 and 48 hours, and there was significant

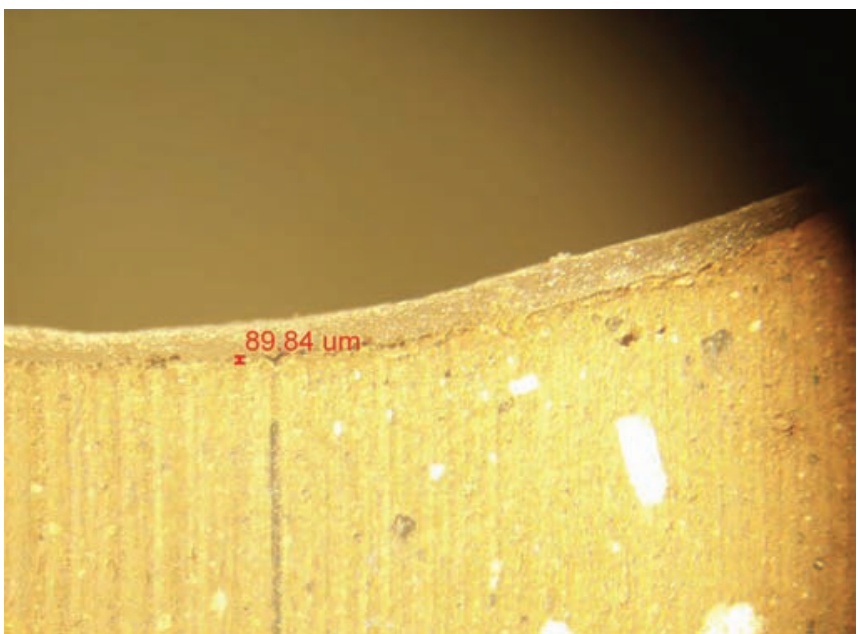

Fig. 4: Midposterior palatal area on brown cast

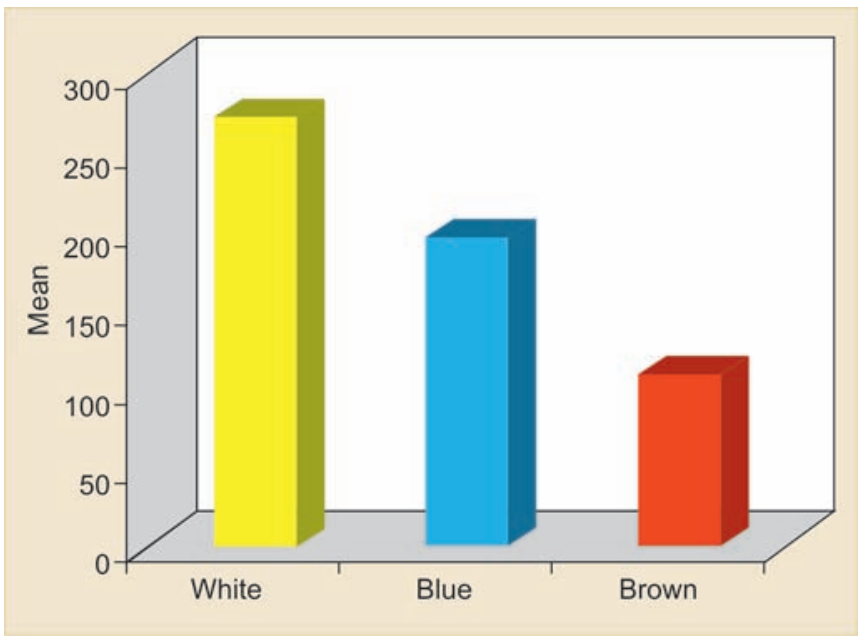

Graph 1: Comparison between the studied groups according to points in 24 hours

increase in accuracy with blue cast in comparison with white cast after 24 hours.

After 48 hours, there was significant decrease in accuracy with blue cast in comparison with brown and white casts. Also, there was insignificant difference in accuracy between results after 24 and 48 hours with trial denture bases, which were constructed on brown and white casts (Graph 1 and 2). 


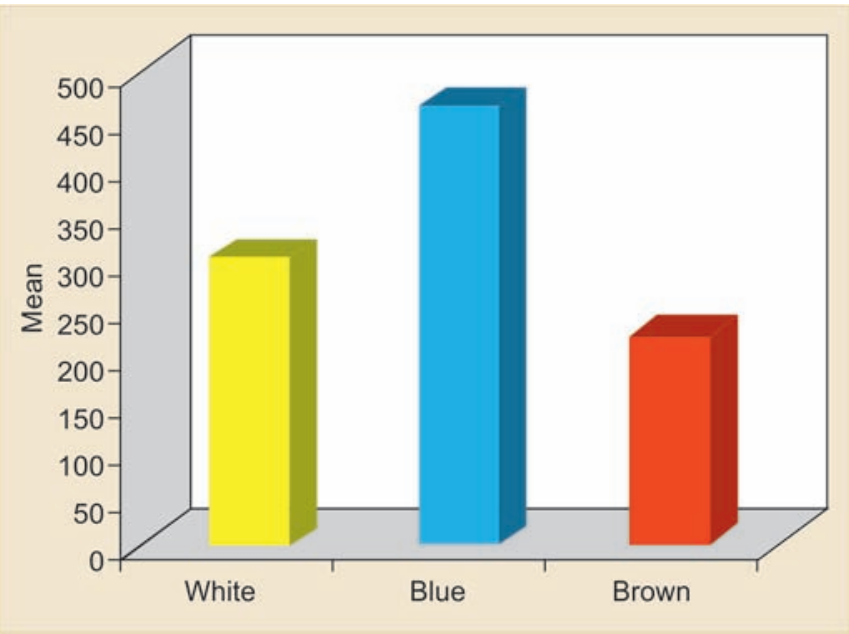

Graph 2: Comparison between the studied groups according to points in 48 hours

\section{DISCUSSION}

In order for a material to succeed as a trial denture base, it must have high impact strength, low density (light weight), dimensional stability (during processing and functions), biocompatibility, ease of manufacture, and low cost.

Visible light-cured resin is characterized by improved physical characteristics, such as increased stiffness, good form, volume stability, and low sensitivity to moisture. In addition, these materials are easy to use and they save time. $^{10-12}$

Hence, the record base should be fabricated in order to be accurately fitted, and it should not change, but remain stable. Even the inaccurate record bases can look well fitted in the palate because of elasticity of soft tissue, but it does not mean that it fits accurately in reality.

The inaccurate record base incurs errors in the final occlusion of complete denture due to the inaccurate jaw relation record. ${ }^{13,14}$

Visible light-polymerizing resins have been reported to be dimensionally stable immediately after complete polymerization with the use of an appropriate light source and exposure time..$^{10,11,15}$

Studies on light-curing resin showed that on being exposed to polymerizing light, the closest material would be polymerized first, which causes the formation of gap due to transformation and contraction. ${ }^{16}$ The reason of such formation of gap with the master cast is the contraction because polymerization and cooling, ${ }^{17}$ and being lifted by internal stress during polymerization. ${ }^{18}$

With the present study, in comparison of accuracies according to the positions, the midpalatal region showed less accuracy than the left and right alveolar crests, and the maximum discrepancy occurred at point $B$ at the posterior border, which is in agreement with the results of previous studies. ${ }^{16,19}$
Therefore, it is recommended that the accuracy of the light-curing resin should be improved through multiple step curing methods ${ }^{18,20}$ or by dividing the VLC sheet into two pieces along the junction of horizontal and vertical configurations of the palate. The stresses that develop during polymerization can be confined within each segment of the material and lead to shifting the direction of shrinkage from the ridge crest area to two separate areas in the middle of the palate and the crest of the ridge. ${ }^{21}$

In the present study, record base was polymerized according to the directions of the manufacturer, but the color of the cast was white for control group, and brown and blue for test group. It was found that trial denture base that was fabricated on brown-colored cast was significantly more accurate in comparison with blue- and white-colored casts after 24 and 48 hours.

Visible light-cured resin is a photopolymer that changes its properties when exposed to light, often in the visible region of the electromagnetic spectrum. ${ }^{22}$

Visible light waves consist of a continuous range of wavelengths or frequencies. When a light wave with a single frequency strikes an object, a number of things could happen. It may be absorbed, reflected, or transmitted. If a light wave of a given frequency strikes a material with electrons having the same vibrational frequencies, then those electrons will absorb the energy of the light wave and transform it into vibrational motion. During its vibration, the electrons interact with neighboring atoms in such a manner so as to convert its vibrational energy into thermal energy. ${ }^{23}$

Such chemicals that are capable of selectively absorbing one or more frequencies of light are known as pigments. These (brown and dark blue) pigments were used to color the casts.

Visible light-cured resin contains photosensitizers, which are compounds that upon radiation of light decompose into reactive species that activate polymerization. ${ }^{24}$

With the present study trial, the denture base that was fabricated on brown and blue casts showed significant increased accuracy because the brown pigment in the cast absorbs all light waves, such as black color, and blue pigment absorbs all waves except blue wave, while white cast reflects all light waves.

Hence, during curing of VLC resin, light absorbed by the photosensitizer and light absorbed by dark color cast are converted into thermal energy to initiate polymerization, so all parts of the trial base which are near or away from the light source were cured at the same time.

\section{CONCLUSION}

Dimensional stability of VLC trial denture base could be improved by using dark-colored cast (brown and dark blue) during construction to ensure accurate 
maxillomandibular relationship and accurate evaluation of phonetics and esthetics of wax trial denture.

\section{ACKNOWLEDGMENTS}

The author specially thanks Pharos students, Mennat Allah Reda, Mohamed Montasser Zeid, Mostafa Kamal, Faten Mohamed Farid, and Eman Ali for their help in laboratory procedures of this research.

\section{REFERENCES}

1. Academy of Prosthodontics. The glossary of prosthodontic terms. 6th ed. J Prosthet Dent 1994;72:41.

2. Elder ST. Stabilized base plates. J Prosthet Dent 1955 Mar;5(2):162-168.

3. Heartwell, CM.; Rahn, AO. Syllabus of complete denture. 4th ed. Philadelphia: Lea and Febiger; 1986. p. 253.

4. Zarb, GA.; Bolender, CL.; Hickey, JC.; Carlsson, GE. Boucher's prosthodontic treatment for edentulous patient. 10th ed. St. Louis: CV Mosby; 1990. p. 296.

5. Ogle RE, Sorensen SE, Lewis E. A new visible light-cured resin system applied to removable prosthodontics. J Prosthet Dent 1986 Oct;56(4):497-506.

6. Philips RW. Skinner's science of dental materials. 9th ed. Philadelphia: WB Saunders; 1991. p. 193.

7. Tan HK, Brudvik JS, Nicholls JI, Smith DE. Adaptation of a visible light-cured denture base material. J Prosthet Dent 1989 Mar;61(3):326-331.

8. Christensen GJ. Now is the time to change to custom impression trays. J Am Dent Assoc 1994 May;125(5):619-620.

9. Pagniano RD, Scherd RC, Clowson RL, Dagefoerde RO, Zardiackes LD. Linear dimensional change of acrylic resins used in the fabrication of custom trays. J Prosthet Dent 1982 Mar;47(3):279-283.

10. Khan SB, Geerts G. Determining the dimensional stability, fracture toughness and flexural strength of light-cured acrylic resin custom tray material. Eur J Prosthodont Restor Dent 2009 Jun;17(2):67-72.
11. Elkholy S. Evaluation of dimensional stability of visible light cured custom tray for complete denture. Egyptian Dent J 2011 Apr;57(1585):1593.

12. Larry CB, Donna LD, Jon PM. Custom impression trays. J Prosthet Dent 1994;71:316-318.

13. Yurkstas AA, Kapur KK. Factors influencing centric relation records in edentulous patients. J Prosthet Dent 1964 Dec;14(6):1054-1064.

14. Schoen PE, Stewart JL. The effect of temporary bases on the accuracy of centric jaw relationship. J Prosthet Dent 1967 Sep;18(3):211-216.

15. Wirz J, Jaeger K, Schmidli F. Light-polymerized materials for custom impression trays. Int J Prosthodont 1990 JanFeb;3(1):64-71.

16. Chen JC, Lancefield WR, Castleberry DJ. Effect of denture thickness and curing cycle on the dimensional stability of acrylic resin denture bases. Dent Mater 1988 Feb;4(1):20-24.

17. Elahi JM, Abdullah MA. Effect of different polymerization techniques on dimensional stability of record bases. J Prosthet Dent 1994 Feb;71(2):150-153

18. Choi HJ, Lim JH, Jo IH. A study on the accuracy of the record base of the complete denture to the master cast according to kinds of resin and polymerization method. J Korean Acad Prosthodont 2000 Jun;38(3):310-320.

19. Shaaban SA. The heat-cured and the self-cured types of acrylic resins regarding: strength, hardness and dimensional stability before and after recuring. Alexandria (Egypt): Dental School, Alexandria University; 1969. p. 238.

20. Oh WS, May KB. Two-stage technique for optimum fit and stability of light-polymerized record bases. J Prosthet Dent 2008 May;99(5):410-411.

21. Fatihallah AA, Mohamed MR, Zia KG. Evaluation of dimensional stability for denture bases in different curing techniques. Mustansiria Dent J 2009;6:389-394.

22. Eichmanis E, Crivello J. Photopolymer materials and processes for advanced technologies. Chem Mater 2013 Nov;26(1):533-548.

23. West, W. Absorption of electromagnetic radiation [Internet]. AccessScience, McGraw-Hill Education, 2014, http:// accessscience.com//content/absorption-of-electromagneticradiation $/ 001600$.

24. Glossary of terms used in photochemistry (IUPAC Recommendations 1996). p. 2265. 